\title{
CPW-Fed Wideband Circular Polarized Antenna for UHF RFID Applications
}

\author{
Sun-Woong Kim, ${ }^{1}$ Guen-Sik Kim, ${ }^{1}$ and Dong-You Choi ${ }^{2}$ \\ ${ }^{1}$ Department of Information and Communication Engineering, Graduate School, Chosun University, Gwangju, Republic of Korea \\ ${ }^{2}$ Department of Information and Communication Engineering, Chosun University, Gwangju, Republic of Korea \\ Correspondence should be addressed to Dong-You Choi; dychoi@chosun.ac.kr
}

Received 21 March 2017; Revised 10 May 2017; Accepted 6 June 2017; Published 16 July 2017

Academic Editor: Ikmo Park

Copyright (c) 2017 Sun-Woong Kim et al. This is an open access article distributed under the Creative Commons Attribution License, which permits unrestricted use, distribution, and reproduction in any medium, provided the original work is properly cited.

We propose a wide bandwidth antenna with a circular polarization for universal Ultra High Frequency (UHF) radio-frequency identification (RFID) reader applications. To achieve a wide $3 \mathrm{~dB}$ axial ratio (AR) bandwidth, three T-shaped microstrip lines are inserted into the ground plane. The measured impedance bandwidth of the proposed antenna is $480 \mathrm{MHz}$ and extends from 660 to $1080 \mathrm{MHz}$, and the $3 \mathrm{~dB}$ AR bandwidth is $350 \mathrm{MHz}$ and extends from 800 to $1155 \mathrm{MHz}$. The radiation pattern is a bidirectional pattern with a maximum antenna gain of $3.67 \mathrm{dBi}$. The overall size of the proposed antenna is $114 \times 114 \times 0.8 \mathrm{~mm}^{3}$.

\section{Introduction}

Radio-frequency identification (RFID) technology is used in devices that transmit and receive information using radio frequency $(\mathrm{RF})$ from electronic tags attached to objects in various applications. The RFID frequency bands are the HF band at $13.56 \mathrm{MHz}$, UHF band from 860 to $960 \mathrm{MHz}$, and ISM band at $2.4 \mathrm{GHz}[1,2]$. RFID applications in the UHF band use different frequency bands in different countries. The frequency bands used are as follows: $902-928 \mathrm{MHz}$ in North America, $840.5-844.5 \mathrm{MHz}$ and $920.5-924.5 \mathrm{MHz}$ in China, $950-956 \mathrm{MHz}$ in Japan, $866-869 \mathrm{MHz}$ in Europe, 920-926 MHz in Australia, 865-867 MHz band in India, and 908.5-914 MHz in South Korea [3-5]. The (UHF) RFID full coverage band in each country is about $840-960 \mathrm{MHz}$.

In the UHF band RFID system, the antenna plays an important role in the communications between the reader and tag. The characteristics of the antenna determine the recognition distance between the reader and the tag. To maximize the distance, the return loss characteristics of the antenna should be as small as possible in the operating frequency band, and the antenna should be designed with a circular polarization [6-8].

In this paper, we describe the design and fabrication of an antenna with circular polarization for an RFID reader in the UHF band. In terms of impedance matching, we used three microstrip lines to achieve an impedance of $-10 \mathrm{~dB}$ across the wide application band. We also used a T-shaped microstrip line to induce a circular polarization characteristic.

\section{Antenna Design}

The structure of the proposed antenna is shown in Figure 1. It was fabricated using an FR4 substrate with a relative permittivity of 4.5 , loss tangent of 0.02 , and thickness of $0.8 \mathrm{~mm}$. The substrate was square with a side length $G$, and the overall size was $114 \times 114 \mathrm{~mm}^{2}$ [9-11]. The feed structure of the antenna used a coplanar waveguide (CPW) structure. The geometric parameters of the L-shaped microstrip lines were $L_{2}, L_{2 \_1}, W_{2}$, and $W_{2 \_1}$. For impedance matching, we used three microstrip lines with geometric parameters of $L_{3}$, $L_{3 \_}, L_{3 \_}$, and $W_{3}$. The geometric parameters of the T-shaped microstrip line used for the circular polarization were $L_{1}$, $L_{1 \_1}$, and $W_{1}$. The fabricated antenna is shown in Figure 2.

The design process used for the antenna consisted of three steps, which are illustrated in Figure 3.

The reflection coefficients and axial ratio (AR) simulation characteristics of the three steps were analyzed using HFSS version 12, and the results are shown in Figure 4. 


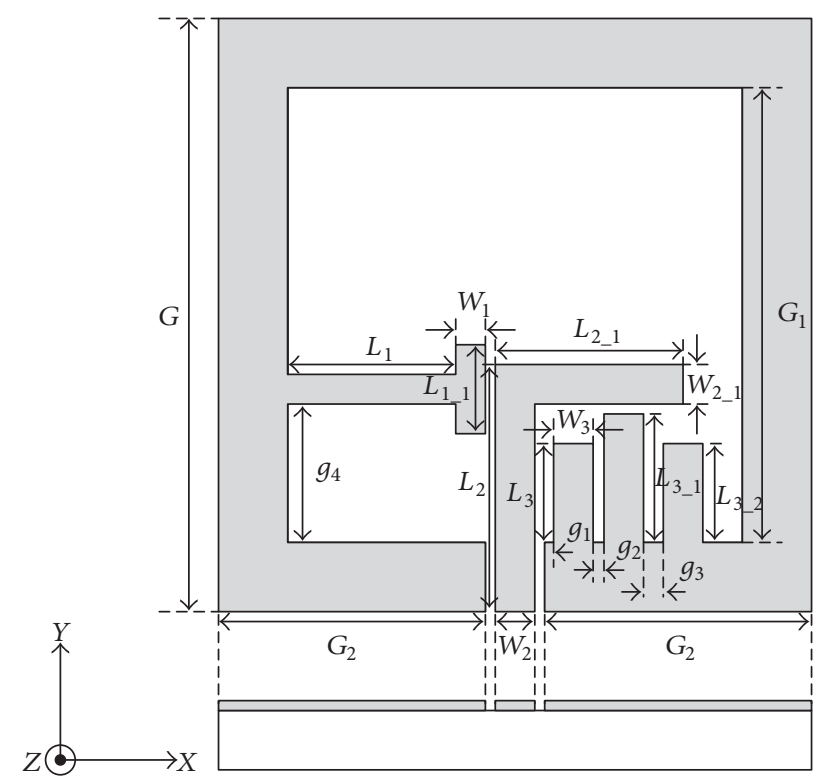

FIgURE 1: Structure and dimensions (in $\mathrm{mm}$ ) of the proposed antenna: $G=114, G_{1}=86, G_{2}=53, L_{1}=35, L_{1 \_1}=16, W_{1}=$ $4, L_{2}=45, W_{2}=5, L_{21}=35, W_{21}=5, L_{3}=20, L_{31}=$ $24, L_{3 \_}=15, W_{3}=5, g_{1}=0.5, g_{2}=2, g_{3}=3$, and $g_{4}=25$.

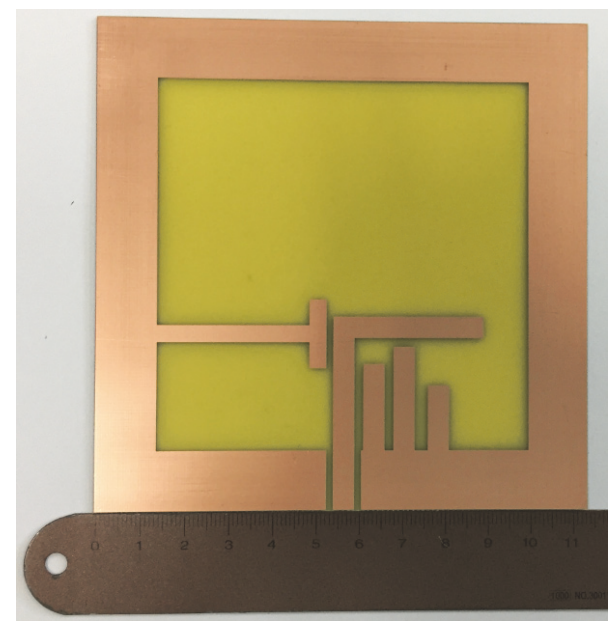

Figure 2: Photograph of the fabricated antenna.

Antenna 1 is a basic antenna with a CPW L-shaped feed structure. It exhibited a good impedance matching characteristic, and a $-10 \mathrm{~dB}$ reflection coefficient bandwidth was achieved over a wide bandwidth of $331 \mathrm{MHz}$ from 739 to $1070 \mathrm{MHz}$. However, it did not achieve the desired $3 \mathrm{~dB}$ axial ratio bandwidth (ARBW). In Antenna 2, a Tshaped microstrip line was added to improve the $3 \mathrm{~dB} A \mathrm{AR}$ characteristics. The resulting antenna exhibited a suitably wide bandwidth of $345 \mathrm{MHz}$ from 772 to $1117 \mathrm{MHz}$, although the impedance matching was poor. Therefore, in Antenna 3 , the impedance was connected to the ground of the three microstrip lines. As a result, a $-10 \mathrm{~dB}$ reflection coefficient bandwidth of $480 \mathrm{MHz}$ from 714 to $1194 \mathrm{MHz}$ was achieved, and the $3 \mathrm{~dB}$ ARBW was $380 \mathrm{MHz}$ from 775 to $1155 \mathrm{MHz}$.
TABLE 1: Detailed results of the proposed antenna for various Tshaped microstrip line lengths.

\begin{tabular}{lcc}
\hline$L_{1}(\mathrm{~mm})$ & $L_{2}(\mathrm{~mm})$ & $3 \mathrm{~dB}$ ARBW $(\mathrm{MHz})$ \\
\hline 35 & 10 & 209 \\
35 & 12 & 212 \\
35 & 14 & 291 \\
$\mathbf{3 5}$ & $\mathbf{1 6}$ & $\mathbf{3 8 0}$ \\
35 & 18 & 338 \\
35 & 20 & 342 \\
\hline
\end{tabular}

The $3 \mathrm{~dB}$ ARBW results for the values of $L_{1}, L_{2}$ of the Tshaped microstrip line are shown in Figures 5(a) and 5(b). The analyzed $3 \mathrm{~dB}$ ARBW values along with the tested values of $L_{1}$ and $L_{2}$ are listed in Table 1 . As shown in the table, better results were observed when the values of $L_{1}$ and $L_{2}$ were 35 and 16, respectively. The corresponding measured $3 \mathrm{~dB}$ ARBW value was $380 \mathrm{MHz}$, which is considered to be a good result based on our earlier discussion.

\section{Experiment Results and Analysis}

The impedance bandwidth of the manufactured antenna was measured using a Network Analyzer (Agilent Co.), and the results are shown in Figure 6.

The simulated $-10 \mathrm{~dB}$ reflection coefficient bandwidth of the proposed antenna extended from 714 to $1194 \mathrm{MHz}$ $(480 \mathrm{MHz})$, and the fractional bandwidth was $50.3 \%$. The measured $-10 \mathrm{~dB}$ reflection coefficient bandwidth of the manufactured antenna was $660-1080 \mathrm{MHz}(420 \mathrm{MHz})$, and the fractional bandwidth was $48.27 \%$.

The simulated and measured $3 \mathrm{~dB}$ ARBW results of the manufactured antenna are shown in Figure 7.

The simulated $3 \mathrm{~dB}$ ARBW of the proposed antenna is $775-1155 \mathrm{MHz}(380 \mathrm{MHz})$, and the measured $3 \mathrm{~dB}$ ARBW of the manufactured antenna is about $800-1150 \mathrm{MHz}$ (350 MHz).

The radiation pattern of both simulated and measured values, for the $X Z$ - and $Y Z$-planes in the $800-1100 \mathrm{MHz}$ band, and the results are shown in Figure 8.

The radiation pattern of the proposed antenna exhibited good bidirectional characteristics.

In addition, right-hand circular polarized radiation (RHCP) was radiated along the front side of the proposed antenna, and left-hand circular polarized radiation was radiated along the back side of the proposed antenna. The maximum gain of the proposed antenna (RHCP and LHCP) was concentrated along the $+z$-axis and $-z$-axis.

The gain and radiation efficiency results of the proposed antenna are shown in Figure 9.

The gain analysis results fluctuated between 3.4 and $3.8 \mathrm{dBi}$ from 750 to $1000 \mathrm{MHz}$. The measured maximum gain was $3.67 \mathrm{dBi}$ at $750 \mathrm{MHz}$, and the simulated maximum gain of $3.8 \mathrm{dBi}$ was observed at $1000 \mathrm{MHz}$. The proposed antenna observed a radiation efficiency of over $90 \%$ in impedance bandwidth both simulated and measured results.

The comprehensive results of the proposed antenna are listed in Table 2 and include a wide bandwidth and measured 


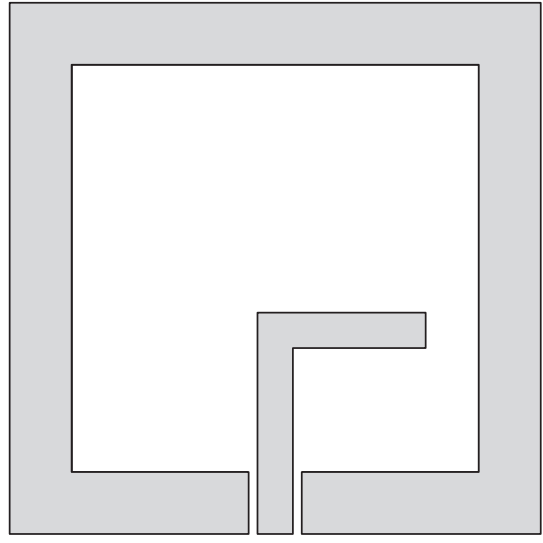

(a) Antenna 1

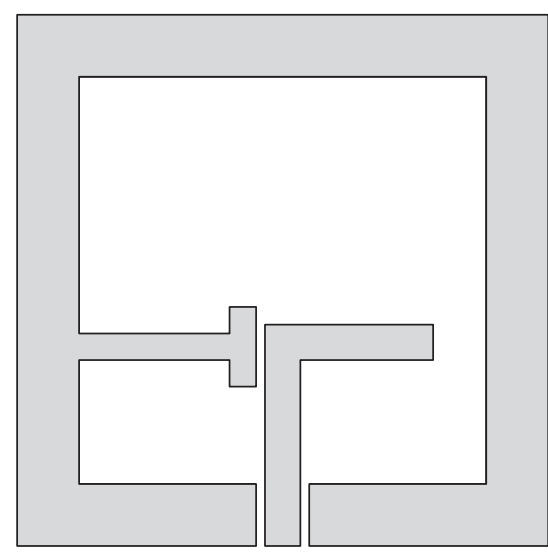

(b) Antenna 2

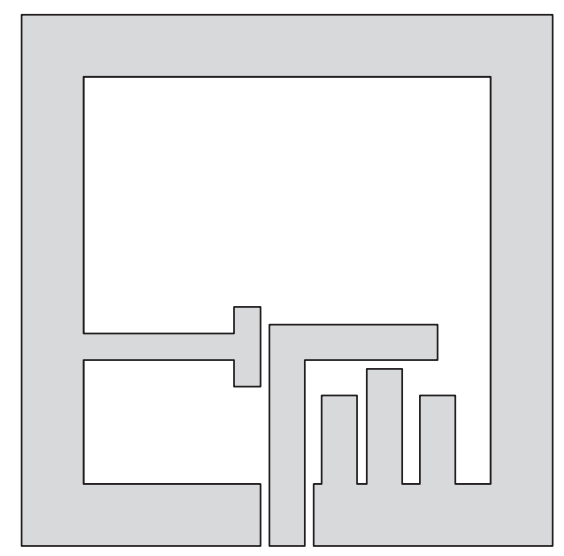

(c) Antenna 3 (proposed)

FIGURE 3: Three steps in the antenna design process.

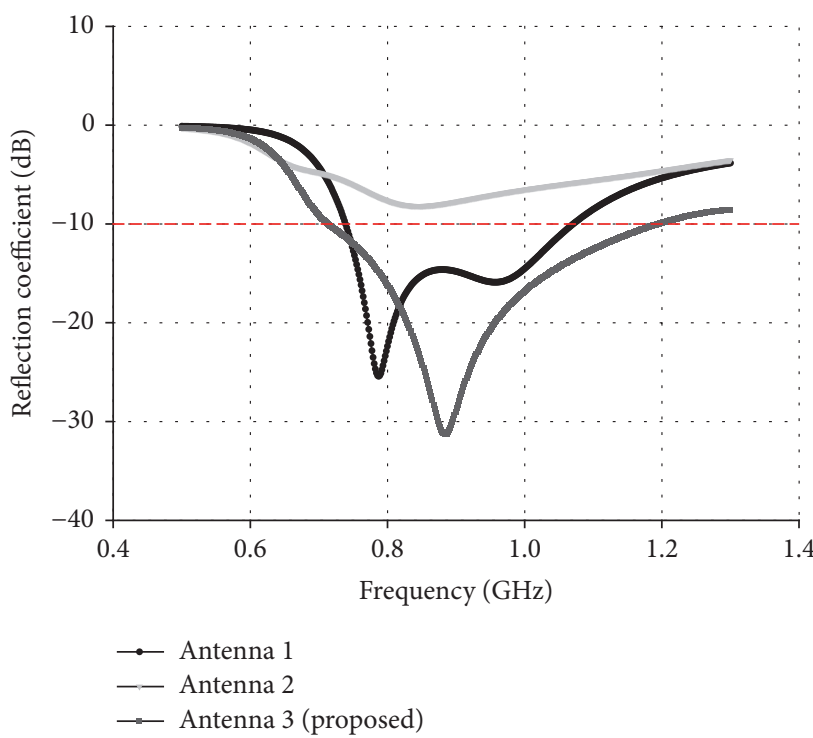

(a) Reflection coefficient

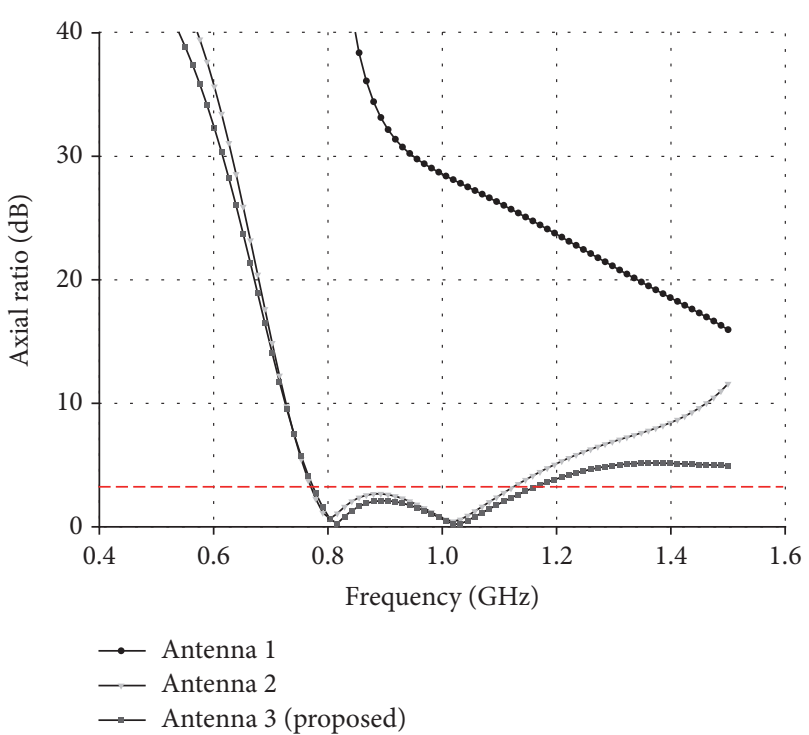

(b) Axial ratio

FIGURE 4: Simulation analysis results of the three methods.

TABLE 2: Comprehensive results of the proposed antenna.

\begin{tabular}{lcc}
\hline & Simulated & Measured \\
\hline -10 dB reflection coefficient range [MHz] & $714-1194$ & $660-1080$ \\
Impedance bandwidth [MHz] & 480 & 420 \\
Fractional bandwidth [\%] & 50.3 & 48.27 \\
Resonant frequency [MHz] & 1000 & 900 \\
Maximum gain [dBi] & 3.8 & 3.67
\end{tabular}

and simulated gain results that were in good agreement. However, there were subtle differences between the simulated and measured results. There were two reasons for these differences. The first was an error during the manufacturing process, and the second was loss between the antenna and connector. The subtle difference is not a problem at the performance of the proposed antenna.
The proposed antenna is compared to other antennas with UHF band for RFID reader in Table 3. The advantage of the proposed antenna lies in its wideband bandwidth and the fact that it has a relatively small size. In order to achieve the proposed antenna, a wide ARBW and wide impedance bandwidth through three microstrip lines and Tshaped microstrip lines are used.

\section{Conclusion}

The proposed antenna exhibited circular polarized wideband characteristics. A T-shaped microstrip line induced the circular polarization characteristics and $3 \mathrm{~dB} A R B W$. In addition, the wideband characteristics were matched due to the three microstrip lines. The overall size of the fabricated antenna was $114 \times 114 \times 0.8 \mathrm{~mm}^{3}$.

The measured impedance bandwidth $(-10 \mathrm{~dB}$ reflection coefficient) results were $420 \mathrm{MHz}$ from 660 to $1080 \mathrm{MHz}$, and 


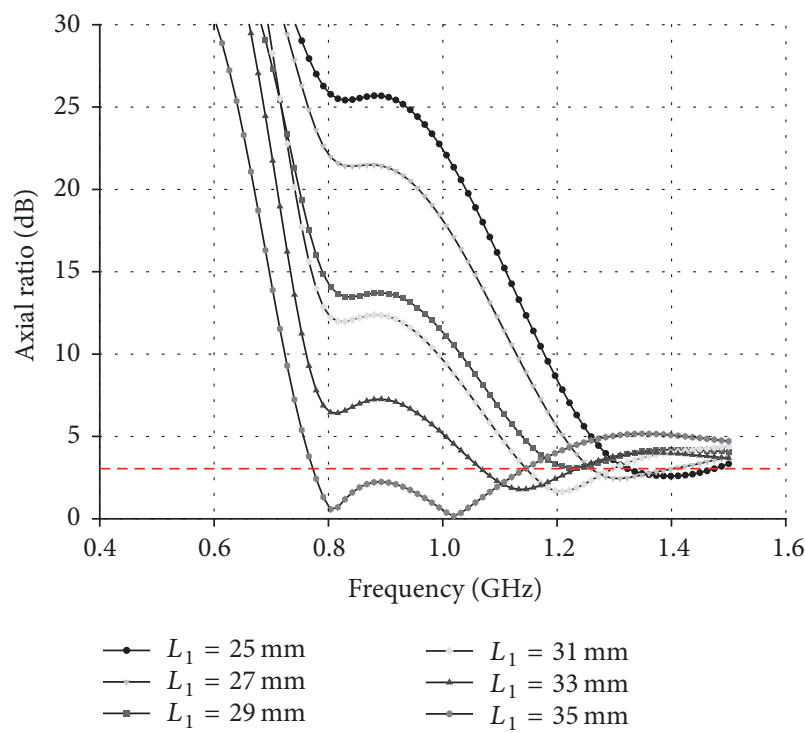

(a) $L_{1}$

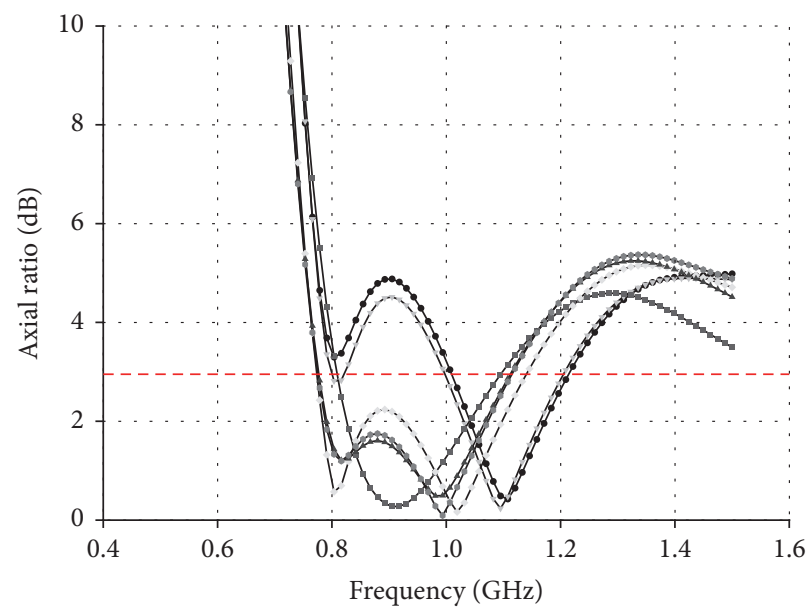

$\rightarrow L_{1}=35 \mathrm{~mm}, L_{1 \_1}=10 \mathrm{~mm} \quad--L_{1}=35 \mathrm{~mm}, L_{1 \_1=16} \mathrm{~mm}$ $\longrightarrow L_{1}=35 \mathrm{~mm}, L_{1-1}=12 \mathrm{~mm} \longrightarrow L_{1}=35 \mathrm{~mm}, L_{1 \_1}=18 \mathrm{~mm}$ $\rightarrow L_{1}=35 \mathrm{~mm}, L_{1 \_1}=14 \mathrm{~mm} \longrightarrow L_{1}=35 \mathrm{~mm}, L_{1 \_1}=20 \mathrm{~mm}$

(b) $L_{2}$

FIGURE 5: Three $\mathrm{dB}$ axial ratios of the proposed antenna with various $L_{1}, L_{1 \_1}$ values.

TABLE 3: Comparison of the proposed antenna and different antenna.

\begin{tabular}{|c|c|c|c|c|}
\hline Antennas & $\begin{array}{c}-10 \mathrm{~dB} \\
S_{11} \text { BW }[\mathrm{MHz}] \\
\end{array}$ & $\begin{array}{c}3 \mathrm{~dB} \\
\text { ARBW }[\mathrm{MHz}]\end{array}$ & $\begin{array}{l}\text { Gain } \\
{[\mathrm{dBi}]} \\
\end{array}$ & $\begin{array}{c}\text { Dimensions } \\
{\left[\mathrm{mm}^{3}\right]}\end{array}$ \\
\hline [3] & $904-941 / 37$ & $918-929 / 11$ & 3.8 & $90 \times 90 \times 4.572$ \\
\hline [4] & $618-998 / 480$ & $791-1123 / 332$ & 3.4 & $120 \times 120 \times 0.8$ \\
\hline [12] & $860-930 / 70$ & - & 3.7 & $110 \times 110 \times 5$ \\
\hline [13] & $891-928 / 37$ & $907-915 / 8$ & 5.85 & $54 \times 54 \times 1.6$ \\
\hline [14] & $\begin{array}{l}820-880 / 60 \\
830-928 / 98\end{array}$ & $\begin{array}{l}864-887 / 19 \\
899-913 / 14\end{array}$ & 1.6 & $90 \times 90 \times 1.6$ \\
\hline [15] & $902-928 / 26$ & $900-936 / 36$ & 1.35 & $105 \times 90 \times 1.6$ \\
\hline Proposed antenna & $660-1080 / 420$ & $775-1155 / 380$ & 3.67 & $114 \times 114 \times 0.8$ \\
\hline
\end{tabular}

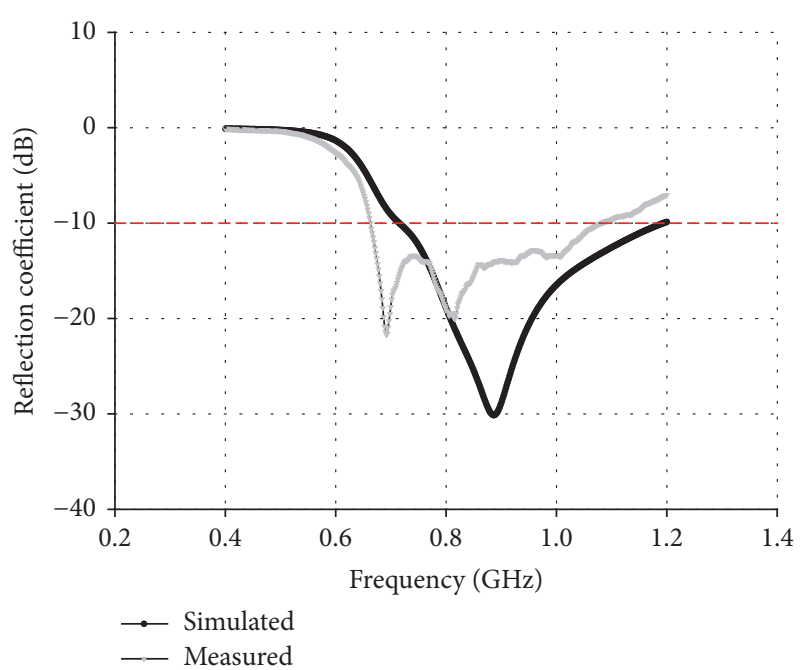

FIGURE 6: Simulated and measured reflection coefficient results of the manufactured antenna.

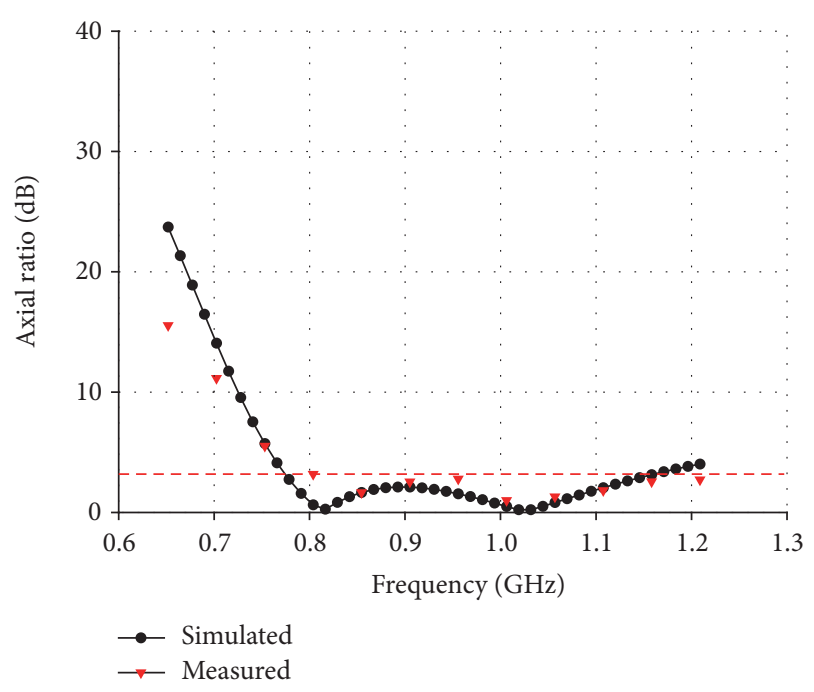

FIGURE 7: Simulated and measured AR bandwidth results of the manufactured antenna. 

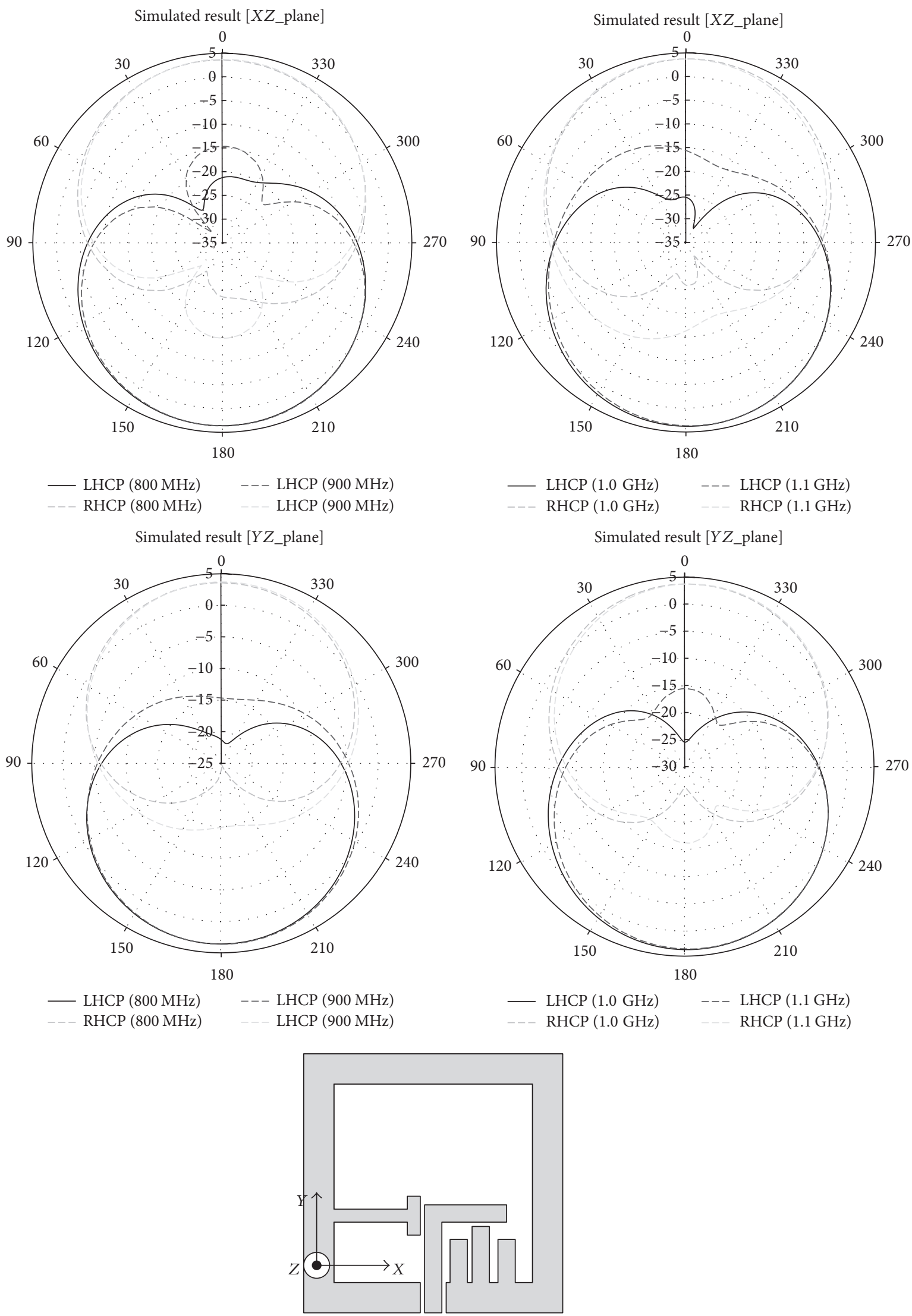

(a) Simulated radiation pattern result

FIgURE 8: Continued. 

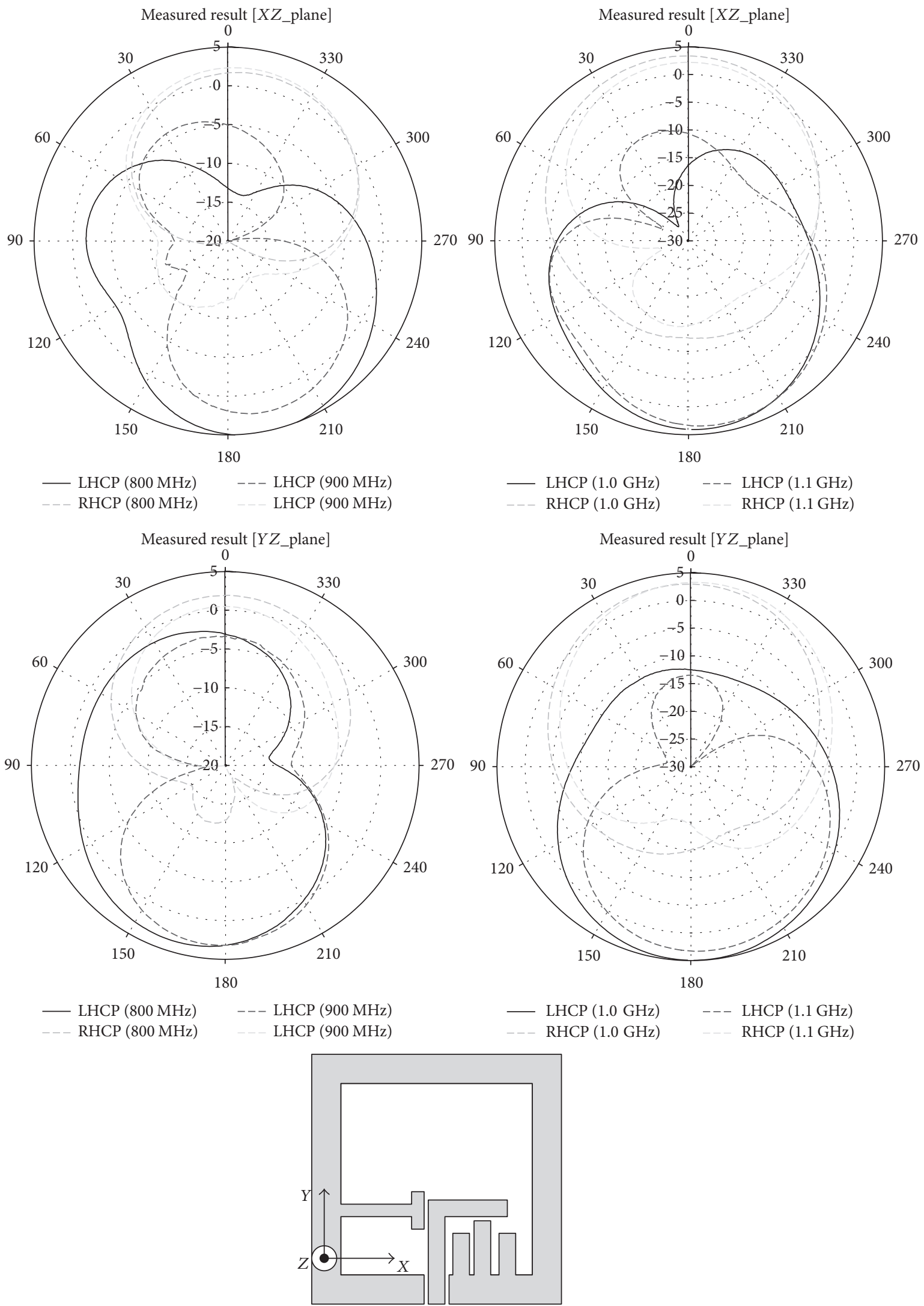

(b) Measured radiation pattern result

FIGURE 8: Radiation pattern of the manufactured antenna. 


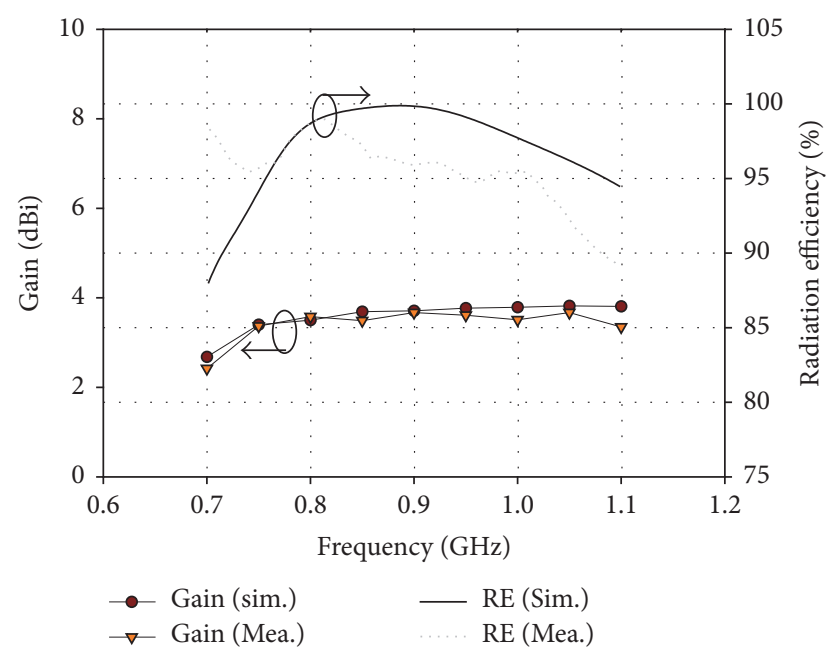

FIGURE 9: Gain and radiation efficiency results of the manufactured antenna.

the $3 \mathrm{~dB}$ ARBW results were $350 \mathrm{MHz}$ from 800 to $1155 \mathrm{MHz}$. The analysis of the radiation pattern showed a bidirectional pattern and a maximum measured antenna gain of $3.67 \mathrm{dBi}$.

The results of a comprehensive analysis of both the measurements and simulation were in good agreement.

\section{Conflicts of Interest}

The authors declare that they have no conflicts of interest.

\section{Acknowledgments}

This research was supported by the Basic Science Research Program through the National Research Foundation of Korea (NRF) funded by the Ministry of Education (2016R1D1A1B03931806).

\section{References}

[1] J. Lim, B. Kang, J. Jwa, H. Kim, and D. Yang, "RFID Reader antenna with hilbert curve fractal structure over partially grounded plane," The Journal of the Korea Contents Association, vol. 7, no. 4, pp. 30-38, 2007.

[2] Y. Jin, J. Tak, and J. Choi, "Quadruple band-notched trapezoid UWB antenna with reduced gains in notch bands," Journal of Electromagnetic Engineering and Science, vol. 16, no. 1, pp. 3543, 2016.

[3] Nasimuddin, Z. N. Chen, and X. Qing, "Asymmetric-circular shaped slotted microstrip antennas for circular polarization and RFID applications," IEEE Transactions on Antennas and Propagation, vol. 58, no. 12, pp. 3821-3828, 2010.

[4] R. Cao and S.-C. Yu, "Wideband compact CPW-fed circularly polarized antenna for universal UHF RFID reader," IEEE Transactions on Antennas and Propagation, vol. 63, no. 9, pp. 4148-4151, 2015.

[5] J. H. Yoon, S. J. Ha, and Y. C. Rhee, "A novel monopole antenna with two arc-shaped strips for WLAN/WiMAX application," Journal of Electromagnetic Engineering and Science, vol. 15, no. 1, pp. 6-13, 2015.
[6] J. H. Ju and J. H. Chun, "A study on the antenna design of the RFID reader for $900 \mathrm{MHz}$ band," Journal of Communications and Networks, vol. 33, no. 12, pp. 473-478, 2008.

[7] S.-W. Kim and D.-Y. Choi, "Compact filtering monopole patch antenna with dual-band rejection," SpringerPlus, vol. 5, no. 1, article no. 883, 2016.

[8] S.-W. Kim and D.-Y. Choi, "Implementation of rectangular slitinserted ultra-wideband tapered slot antenna," SpringerPlus, vol. 5, no. 1, article no. 1387, 2016.

[9] S. Kim, K. Kwon, and J. Choi, "A compact circularly-polarized antenna with enhanced bandwidth for WBAN applications," Microwave and Optical Technology Letters, vol. 55, no. 8, pp. 1738-1741, 2013.

[10] G. Pan, Y. Li, Z. Zhang, and Z. Feng, "A compact wideband slotloop hybrid antenna with a monopole feed," IEEE Transactions on Antennas and Propagation, vol. 62, no. 7, pp. 3864-3868, 2014.

[11] K. J. Kim, W. C. Choi, and Y. J. Yoon, "Circularly rotated array for dual polarized applicator in superficial hyperthermia system," Journal of Electromagnetic Engineering and Science, vol. 15, no. 1, pp. 20-25, 2015.

[12] Z.-J. Tang, J. Zhan, and H.-L. Liu, "Dual-resonance compact circularly polarized reader antenna for UHF RFID applications," Microwave and Optical Technology Letters, vol. 54, no. 11, pp. 2531-2533, 2012.

[13] A. Farswan, A. K. Gautam, B. . Kanaujia, and K. Rambabu, "Design of Koch fractal circularly polarized antenna for handheld UHF RFID reader applications," IEEE Transactions on Antennas and Propagation, vol. 64, no. 2, pp. 771-775, 2016.

[14] R. Cao and C. Kai Wang, "Frequency-reconfigurable circularly polarized antenna for UHF RFID reader," Microwave and Optical Technology Letters, vol. 58, no. 12, pp. 2842-2845, 2016.

[15] C. Raviteja, C. Varadhan, M. Kanagasabai, A. K. Sarma, and S. Velan, "A fractal-based circularly polarized UHF RFID reader antenna," IEEE Antennas and Wireless Propagation Letters, vol. 13, pp. 499-502, 2014. 


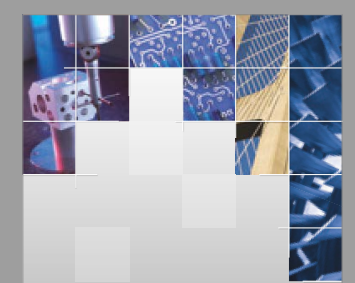

\section{Enfincering}
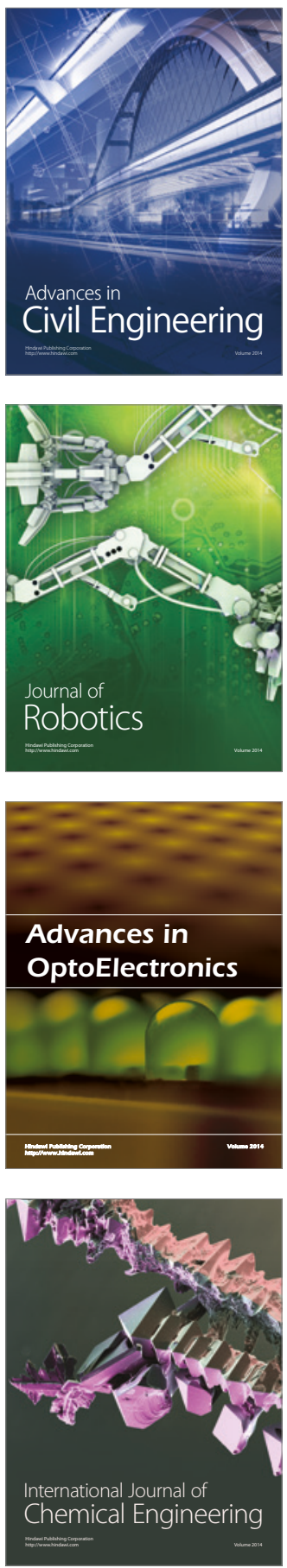

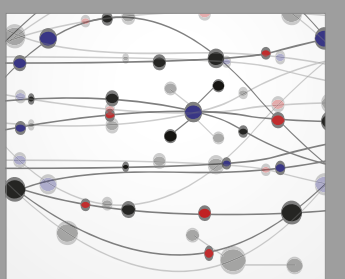

The Scientific World Journal

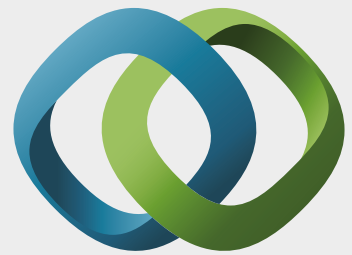

\section{Hindawi}

Submit your manuscripts at

https://www.hindawi.com
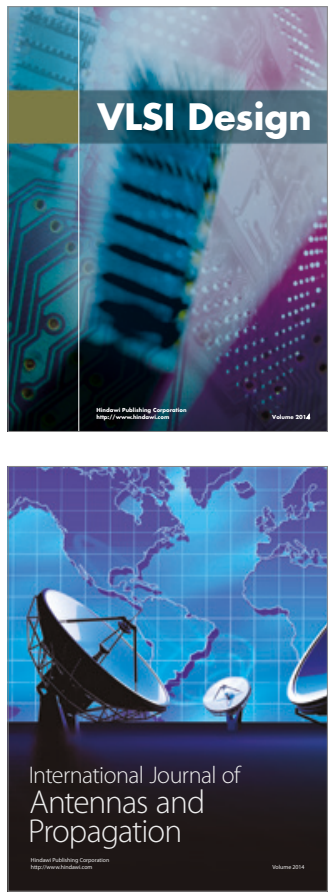

\section{Rotating}

Machinery
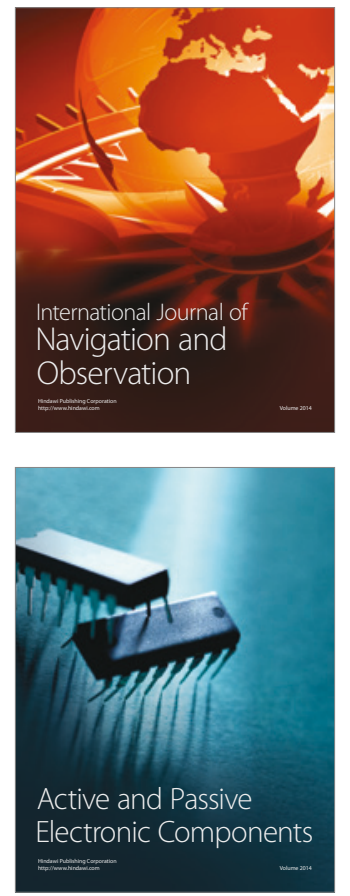
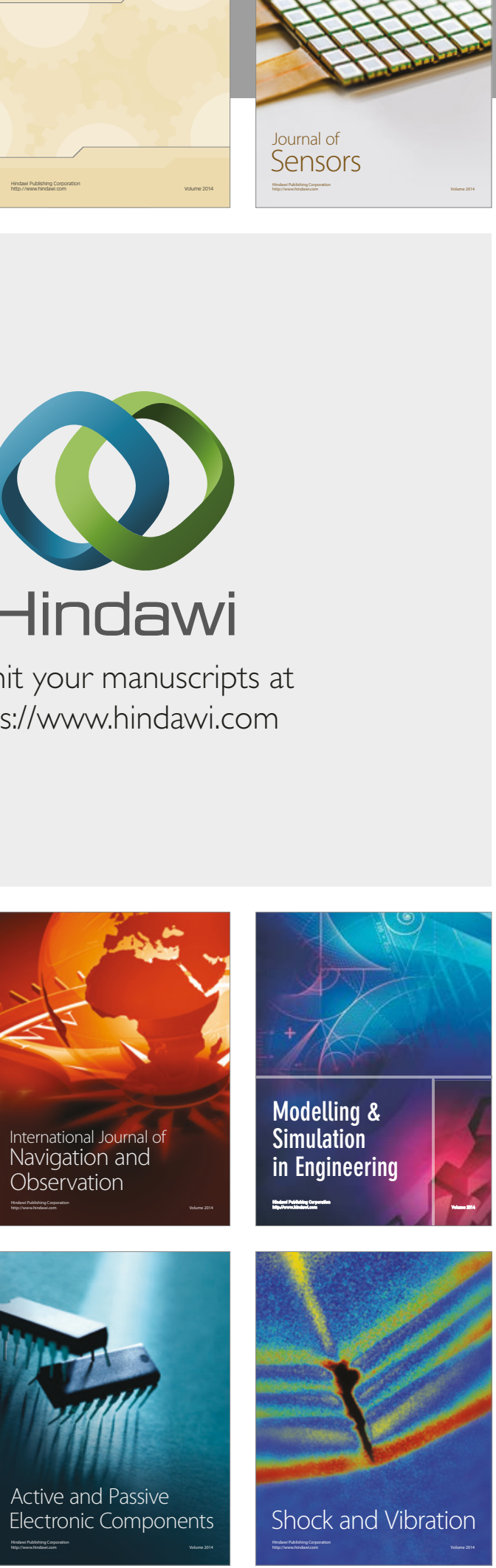
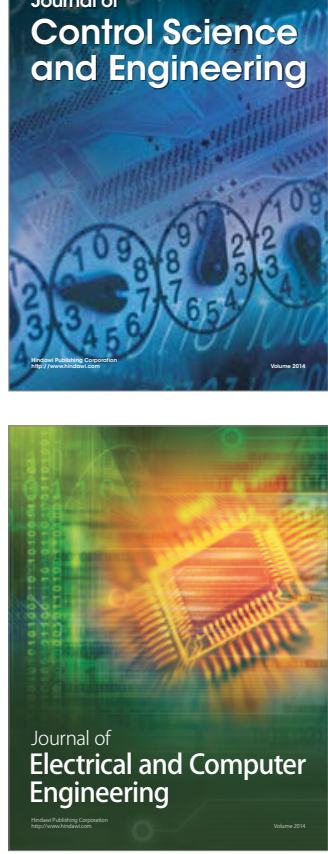

Distributed

Journal of

Control Science

and Engineering
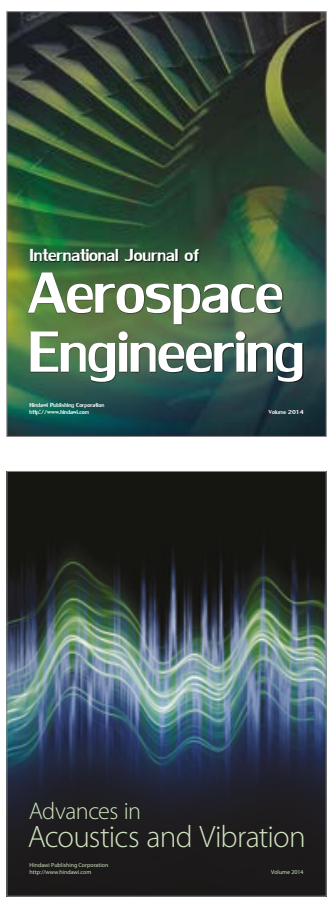

Sensor Networks 